\title{
Naturalism and Metaphors
}

Towards a Rortian Pragmatist Aesthetics

\section{Kalle Puolakka}

\section{(2) OpenEdition}

Electronic version

URL: http://journals.openedition.org/ejpap/878

DOI: $10.4000 /$ ejpap.878

ISSN: 2036-4091

\section{Publisher}

Associazione Pragma

\section{Electronic reference}

Kalle Puolakka, « Naturalism and Metaphors », European Journal of Pragmatism and American

Philosophy [Online], III-1 | 2011, Online since 01 July 2011, connection on 07 May 2019. URL : http:// journals.openedition.org/ejpap/878 ; DOI : 10.4000/ejpap.878

This text was automatically generated on 7 May 2019.

\section{c) $(1)(9$}

Author retains copyright and grants the European Journal of Pragmatism and American Philosophy right of first publication with the work simultaneously licensed under a Creative Commons AttributionNonCommercial-NoDerivatives 4.0 International License. 


\title{
Naturalism and Metaphors
}

\author{
Towards a Rortian Pragmatist Aesthetics
}

\author{
Kalle Puolakka
}

\section{Introduction}

1 The work of Richard Rorty, arguably the most significant neopragmatist philosopher, has received very little support in aesthetics. Rorty's fellow pragmatist Richard Shusterman has presented the most systematic critical assessment of Rorty's work, and some parts of his pragmatist theory are in direct confrontation with Rorty's views. Shusterman's most significant misgivings concerning Rorty's neopragmatism from the point of view of aesthetics are connected with the dominant position he sees Rorty placing on language in the constitution of human experience (Shusterman 1997: 158-62; Shusterman 2006: 227n2). Instead of embracing the view of human experience found in John Dewey's pragmatism that emphasizes its layered character Shusterman equates the conception of experience he sees underpinning Rorty's work with a view called "hermeneutic universalism," which is usually used as a short term for a conception in which language is considered the essential condition of thought and meaningful experience (Shusterman 2000: 238-9, 253-4). Moreover, when the individualistic aestheticism characterizing the activity of "the liberal ironist," the central figure of Rorty's social philosophy, is taken into account, Rorty's views ultimately drift surprisingly far, Shusterman claims, from the democratic and communal aims central to John Dewey's aesthetics (ibid.: 246-50). Hence, a pragmatist conception of aesthetics must be built on a different kind of ground than Rorty's work provides.

2 Shusterman's criticism of Rorty's neopragmatism, however, is by no means unproblematic. By criticizing Rorty's work for slipping into a view which he terms "linguistic mentalism" (ibid.: 258), Shusterman arguably associates Rorty's neopragmatism with a philosophical conception known as "linguistic idealism," a metaphysical doctrine which sees reality as essentially language-constructed. This kind of reading of Rorty's work has in recent commentary literature been seen to provide a highly misguided view of its philosophical underpinnings. ${ }^{1}$ The significance of this body 
of literature in this context is that it directs the focus onto an aspect of Rorty's neopragmatism that Shusterman does not take properly into consideration in his critical reading of Rorty's work. This is the connection Rorty's neopragmatism bears to the tradition of naturalistic philosophy. The basic tenet of Rorty's naturalism maintains that a human's relationship to his or her surroundings is constructed purely causally in the sense that it does not contain any kinds of mediating elements, such as mental representations. This naturalistic outlook serves as a foundation for Rorty's critique of empiricist conceptions of knowledge that he supplements with the idea of "the myth of the given" introduced by Wilfrid Sellars.

3 Taking up the naturalism characterizing Rorty's neopragmatism and the critique of empiricist conceptions of knowledge it involves might seem irrelevant to aesthetics. This, however, is not the case. The full relevance of these parts of Rorty's neopragmatism is revealed once they are connected with a view underlying Rorty's conception of literature, namely Donald Davidson's theory of metaphor. Davidson's account of metaphor is important for Rorty's general naturalistic outlook, for, in his opinion, it provides an ample framework for explaining the significance and value of art, literature and other similar phenomena in the context of naturalistic philosophy. Davidson's view, in other words, implies that "a proper acknowledgement of the cultural role of imaginative literature (and, more generally, of art, myth, and religion - all the 'higher' things) is [not] incompatible with a naturalistic philosophy" (Rorty 1991: 124).

Observing the influence of Davidson's theory of metaphor on Rorty's conception of literature deepens the problems of Shusterman's critique of Rorty's neopragmatism. This is because the decisive feature of Davidson's view of metaphor which separates it from other influential accounts is that it does not explain the work of metaphor by assuming metaphors possess a second, metaphorical level of meaning above the literal meanings of utterances that is assumed to ground the content of a metaphorical expression (Davidson 1984/78: 245). Instead, Davidson unpacks the mystery of metaphors by concentrating on the effects metaphorical uses of language cause. Davidson does acknowledge that metaphors "make us notice aspects of things we did not notice before, bring surprising analogies and similarities to our attention and [...] provide a kind of lens" (ibid.: 261). What Davidson, however, denies is that "metaphor does its work by having a special meaning, a specific cognitive content" (ibid.: 262). This is in other words to say that in the Davidsonian scheme, the work of metaphor is not primarily explained in linguistic terms. This is also shown by Rorty's understanding of Davidson's approach, for he compares the effects metaphors are described as having on conversations in the Davidsonian model with the effects such phenomena as slapping one's interlocutor's face or kissing him have in similar situations (Rorty 1989: 18). Rorty, in fact, explicitly calls the phenomena, the effects of which bear a likeness to the effects of metaphors, "non-linguistic" (Rorty 1991: 167).

In the following paper, I shall discuss Rorty's conception of literature in light of the effect Davidson's theory of metaphor had on it, as well as re-examine the relevance of Rorty's neopragmatism for pragmatist conceptions of aesthetics and philosophy of art. Though it will form a sort of background, dwelling on the problems of Shusterman's critique of Rorty will not play a major role in the paper. I raise this issue primarily to situate my own stance on Rorty's pragmatism within some other readings it has received in philosophy of art. 
6 I begin the paper by examining the impact Davidson's account had on the view of metaphor Rorty's neopragmatist naturalism includes. One way in which the high prospects Rorty assigns to Davidson's ideas in explaining art's significance within a naturalistic framework can be illuminated is by way of examining the role Rorty sketches for metaphors in his postmetaphysical liberalist culture, and especially the value he sees them having in enhancing one of the central values of this kind of society, namely solidarity. Rorty does not himself connect his naturalistic account of metaphor with the social role he attaches to metaphors that explicitly. My belief is that the more fully worked out reading of this connection I shall offer provides new insights into the reasons that make metaphors valuable for Rorty's postmetaphysical liberalist cultural aims. This investigation is also significant with respect to Shusterman's critique of Rorty, for I believe it shows that there is a strong communal aspect in Rorty's thinking on aesthetics and literature that readings addressing Rorty's views through the notion of the liberalist ironist, such as Shusterman's, fail to embrace. In fact, my belief is that Rorty's conception of art and literature overlaps in some significant ways with the emphases central for John Dewey's aesthetic theory. I close by outlining some wider implications the fuller account of Rorty's philosophy of literature provided in the paper has for the place of pragmatism within contemporary aesthetics. Pointing out the similarities between Rorty's and Dewey's conceptions of aesthetics will be an important part of this examination. In my opinion, the assessment of Rorty's work I provide shows that Shusterman's view of its relevance for philosophy of art and aesthetics is too negative.

\section{Naturalism and Metaphors in Rorty's Neopragmatism}

7 As Michael Williams points out, to talk of naturalism in connection with Rorty's work may sound strange, given that Rorty's name is usually associated with postmodernism and other such traditions of thought with very different philosophical undercurrents from those characterizing forms of naturalism (Williams 2009: xv). This is especially the case with such fields as aesthetics and philosophy of art. One of the central features of Rorty's naturalism is that, in Rorty's hands, naturalism turns into a purely negative view, in the sense that it rejects certain traditional ways of thinking about the relationship between human beings and their surroundings without, however, offering a detailed positive view in their place which would try to provide more satisfactory analyses about truth, knowledge, and reality, which preoccupy the views it opposes.

In short, the view of human subjectivity Rorty opposes is the idea that we are in touch with our surroundings in terms of representations and that the character of our contact with the world is determined by how closely the representations our minds contain correspond to the way the world actually is. The decisive difference between this deeply grained conception of what it is to be human, which, in Rorty's opinion, has dominated most of modern philosophy, and his naturalism is that in the latter case human's relationship with his or her surroundings is considered purely causal by nature, that is, to put it in Rorty's own words, naturalized theories of the mind and language of the kind he supports make "all questions about the relation of either to the rest of the universe causal questions, as opposed to questions about the adequacy of representation and expression" (Rorty 1989: 15). 
Davidson has helpfully formulated this distinction in terms of a distinction between "causal intermediaries" and "epistemic intermediaries" (Davidson 2001: 144). While sensations do have a causal role in our beliefs, they do not by themselves determine the content of our beliefs and, hence, they cannot serve as reasons for our beliefs (ibid.: 143). This view of justification is in line with the Sellarsian critique of empiricism Rorty draws on, which maintains that sensations are by themselves mute and that they cannot, therefore, be cited as reasons for beliefs but that justification always takes place in "the logical space of reasons." Rorty summarizes the view of the relationship between the mind and the world arising from these different accounts by saying that "the pragmatist recognizes relations of justification holding between beliefs and desires, and relations of causation holding between these beliefs and desires and other items in the universe but not relations of representation" (Rorty 1991: 37).

The kind of naturalism Rorty supports implies a position that many may find unappealing. This is the fact that it does not construe a decisive difference between the character that a human's relationship to the world takes and that characterizing the relationship of other animals. For naturalism, this difference is more a matter of difference of degree than of kind. Both relationships are constructed purely causally, the causal processes involved in human life simply being much more complex in character (Rorty 2007: 113-4).

11 Rorty thinks that a decisive reason why this sort of naturalistic outlook on human subjectivity has been opposed is that it seems to jeopardize the supposed uniqueness of humans among other creatures, as well as the high value we attach to our products like works of literature. One way in which the threat in question here can be expressed is that, as Rorty himself puts it, the naturalistic view of the kind underlying his neopragmatism would seem to imply that we "secrete [...] symphonies as our spleen secretes dark humors" (Rorty 1979: 44).

12 The worry expressed in this response to naturalism, however, is unwarranted. The causal relations constructing our lives do not have their origin solely in natural processes but humans have the power to create artefacts with similar impacts, and in Rorty's view metaphors are among the most powerful tools of this kind. Explaining the development of human life solely by natural causes will take one only so far. An explanation of how humans developed "from the relative mindlessness of the monkey to the full-fledged mindedness of the human [...] takes us off into neurology and thence into evolutionary biology," while an explanation of how we got "from speaking Neanderthal to speaking postmodern [...] takes us into intellectual history as the history of metaphor" (Rorty 1989: 16).

13 Yet, any account of metaphor will not do for Rorty and it is precisely Davidson's theory that Rorty considers a particularly apt basis for developing an explanation of the significance of culture within a naturalistic philosophy. The main reason for this is that it is metaphysically on the same plane as the naturalist outlook he supports. For Rorty, Davidson's view of metaphor does not merely mark an attempt to get hold of a cunning phenomenon of language but it squares well with the concerns of naturalistic philosophy in general. Most importantly, Davidsonian philosophy of language allows us to see language, not as a medium between self and world but as a tool for doing different sorts of things. For Rorty, this view "is part of a larger attempt to get rid of the traditional philosophical picture of what it is to be human" (ibid.: 19). 
What makes Davidson's theory of metaphor naturalistic for Rorty is precisely the rejection it exhibits towards the idea that metaphors carry a special kind of message, that is, that metaphors include, in addition to their literal meaning, a kind of ideal level of meaning that grounds their cognitive content. The general goal of Rorty's naturalistic account of metaphors is to call into question the meaningfulness of explaining the value of art by assuming that art communicates cognitive content in a way similar to some other fields of discourse in our culture, such as science. Instead, Rorty insists, we should try to explain the significance of literature and other cultural artefacts in other ways than by “trying to 'broaden' either semantic or epistemic notions" (Rorty 1991: 163). This is precisely what Davidson's approach to metaphor makes possible, for:

by putting metaphor outside the pale of semantics, insisting that a metaphorical sentence has no meaning other than its literal one, Davidson lets us see metaphors on the model of unfamiliar events in the natural world - causes of changing beliefs and desires - rather than on the model of representations of unfamiliar worlds, worlds which are 'symbolic' rather than 'natural.' (Ibid.)

Effective metaphors make us see things in a different light. Yet, metaphors do not have to be assumed to possess cognitive content to achieve this. Rorty elaborates the naturalistic account of the cognitive value of metaphor with the distinction between causes of beliefs and reasons for beliefs. Metaphors are for him similar to other "unfamiliar noises" we encounter in that their functioning cannot be fully predicted by our present means and they cannot be assigned determinate content by our present cognitive resources. For this reason metaphors cannot serve as reasons for beliefs. This, however, does not deprive metaphors of cognitive significance, for their lack of cognitive content does not imply that they could not have a causal role in shaping our beliefs and desires. Good metaphors make us attend to novel aspects in our environment and they can, thus, make us change our beliefs. This, however, does not mean that the metaphor expresses the novel belief we come to hold as a result of the cognitions the metaphor causes in us. From a naturalistic perspective, it is in other words a mistake to think that a metaphor's capacity to reveal new aspects in one's surroundings is based on its conveying information that we come to acquire as a result of grasping the meaning of the metaphor (ibid.: 169). As Davidson himself explains, "joke or dream or metaphor can, like a picture or a bump on the head, make us appreciate some fact - but not by standing for, or expressing the fact" (Davidson 1984/78: 262).

This is to say that despite their lack of cognitive content, metaphors are nevertheless responsible for a lot of cognitions that may eventually cause us to change our beliefs. This shows how metaphors can be effectual without possessing definitive cognitive content; if a particular metaphor "had not turned up, we would not have been moved [...] to formulate and deploy certain sentences which do have such [cognitive] content" (Rorty 1991: 168). Even though they do not themselves express beliefs or open up symbolic worlds, metaphors, by making us attend to novel aspects in our environment, can have a causal role in the formation of our beliefs. This explains how metaphors can be cognitively significant, that is, how they can change our beliefs without possessing cognitive content of the kind beliefs possess. From Rorty's point of view, the mistake of empiricist conceptions of knowledge and cognitive-idealist theories of metaphor is thus ultimately one and the same, namely a failure to see that "a stimulus to knowledge" does not itself have to convey knowledge (ibid.: 169). 


\section{Metaphors of Solidarity and Imagination}

17 Bringing the naturalistic undercurrents of Rorty's neopragmatism into sharper focus highlights previously unnoticed aspects in his work on philosophy art. It also undermines the critical reading Shusterman has presented of Rorty's work. If metaphors are central means of cultural change and development, and if in Rorty's account their effect is compared, not to the effect linguistic items like beliefs and sentences have on us, but to the effects engendered by various non-linguistic phenomena, it is arguable that Shusterman's understanding of Rorty as a strong textualist is misguided. Recent pragmatist work in aesthetics seems to follow Shusterman's conception of the role of language in Rorty's philosophy rather closely. The strength of these accounts is, however, weakened by their failing to take into consideration the impact of Davidson's view of metaphor on Rorty's view, and how Rorty's philosophy of literature builds on his conception of naturalism. ${ }^{2}$ The slight one-sidedness characterizing the reception of Rorty's work within aesthetics and philosophy of literature is unfortunate, for it has no doubt discouraged attempts at more thorough assessments of its value for aesthetics. I shall provide such an assessment at the end of my paper, and working out the communal aspect of Rorty's thinking on aesthetics revealed by the position metaphors have in his social philosophy, a topic I shall now turn to, will be important for this purpose.

The full import of Davidson's account of metaphor for Rorty's neopragmatism becomes apparent from the position Rorty assigns to literature and metaphors in the postmetaphysical, liberalist society he sketches. Especially solidarity receives an important position in Rorty's view. By solidarity Rorty refers to a feeling of communality between human beings and to the capacity of being alert and sensitive to the kinds of pain and humiliation people may be subjected to. Rorty's account of liberalism is founded on Judith Sklar's view of liberalists as "the people who think that cruelty is the worst thing we do" (Rorty 1989: xv). For Rorty, solidarity is an inherently local phenomenon, which is to say that it has to be constructed out of different pieces in different contexts and perhaps even recreated from the most unexpected elements once new unforeseeable situations emerge, rather than something to be understood in terms of a common human nature people share and as something already waiting for us in advance (Rorty 1989: 94).

The attempt at increasing the "sense of "us" Rorty finds central to the feeling of solidarity requires "skill at recognizing and describing the different sorts of little things around which individuals or communities center their fantasies and their lives" (ibid.: 93). Hence, one capacity receiving an important role in the enhancement of solidarity is imaginative engagement with other people. The sense of us lying at the heart of solidarity requires that we develop ways of discerning similarities and differences between human groups upon which the feeling of communality underlying solidarity can be built. As Rorty explains the importance of imaginative engagement for his position on solidarity, "skill at imaginative identification does the work which the liberal metaphysician would like to have done by a specifically moral motivation - rationality or the love of God [...]" (ibid.).

20 Metaphors are important parts of this imaginative engagement. Since the feeling of solidarity requires perceiving similarities and differences between oneself and those one tries to relate to in a given context, a metaphor achieving this sort of bond becomes an important means of enhancing solidarity. Metaphors can make us notice novel 
similarities between different things and in this respect they have a role in increasing the presence of solidarity. However, it seems that Davidson's naturalistic view of metaphor manages to embrace the role Rorty attributes to metaphors in enhancing solidarity in a particularly apt way. This is because it is in line with the contextual and contingent account of solidarity Rorty offers. This account insists on the impossibility of fixing a permanent ground for developing a method for enhancing the presence of solidarity and instead emphasizes that attempts at increasing solidarity always take place in contingent historical circumstances and that it may thus require unforeseeable building blocks.

The scepticism the naturalistic account of metaphor exhibits towards the idea that metaphors carry a cognitive content implies a highly rich and dynamic view of the effects of metaphors. Metaphors do not transmit belief-like states with a specified content which the receiver, after having grasped the content of the metaphor, places alongside his or her current beliefs, and which he or she then assesses in relation to them, ultimately either rejecting or accepting the belief the metaphor conveys. The naturalistic account provides a different view of the effect of a metaphor. As the metaphor does not say anything more than what the words in their literal meaning express, neither does it straightforwardly tell how the likenesses the metaphor draws attention to should be understood (Davidson 1984/78: 255). This shows that working out the significance of the metaphor requires much more effort and sensitivity of perception than the mere weighing of the validity of a newly encountered belief. In the Davidsonian model, the effects of metaphors thus become highly multi-faceted and intensive phenomena, and the change in beliefs they cause are comparable to an awakening kind of state, like the experience of regaining consciousness after a blow on the head.

Though Rorty does not develop his view of metaphors as one of the central means for enhancing the feeling of solidarity in relation to Davidson's naturalistic account that explicitly, the picture of the engagement with a metaphor that view implies reveals the full significance metaphors may have in furthering the social values central to Rorty's liberalism. The engagement with a metaphor structurally overlaps in some significant respects with the sensitivity and alertness to contextual detail Rorty finds central to the enhancement of solidarity. Metaphors stir the same kind of mental powers that are also at the heart of the construction of solidarity, and thus metaphors become important devices for developing those capacities required in the enhancement of solidarity. There is no common set of rules or axioms with the help of which it could be possible to spell out what the capacity to feel solidarity with one's neighbours in every possible situation requires. Similarly, it is impossible to give a definite list of how the similarities a given metaphor can cause us to see should be understood and the effect the metaphor may have on our beliefs and desires. As in the case of solidarity, all one can do with respect to metaphors is to stay imaginatively alert. In this respect, it is understandable why Rorty thinks that the question "How do metaphors work?" is in fact in no substantial sense different from such questions as "What is the nature of the unexpected?" or "How do surprises work?" (Rorty 1991: 106).

These reflections show that for Rorty the value of metaphors lies primarily in the platform engagements with metaphors afford for the development of the imaginative mental powers central to the enhancement of solidarity. Yet, metaphors are not only important as surprising "unfamiliar noises" but the process in which a metaphor gradually loses its metaphorical quality and as a result of which it begins to resemble literal expressions with a specified and shared content can have valuable outcomes as 
well. The distinction between causes and reasons becomes important once again. According to Rorty, for Davidson the distinction between cognitive content and "mere stimuli" does not mark a definitive and permanent metaphysical divide between different realms of reality, instead it simply concerns how we are prepared to embrace, handle, and account for the things falling under these categories. That is, we can predict expressions with a definitive content, in the sense that we know what beliefs they are used to express and how they are related to other established expressions in our culture. These sorts of noises can be used to express beliefs precisely because they have a role in different patterns of justification, and they can thus serve as reasons for beliefs. However, metaphors as unfamiliar noises, which lack definitive and predictable cognitive content, cannot enter into the patterns of justification.

The functioning of a metaphorical expression however changes as the metaphor begins to lose its metaphorical character, in other words when the metaphor begins to acquire a determinate content similar to that which literal expressions possess. As a result of this development, metaphors "cross the line from 'mere' causes of belief to reasons for belief" (ibid:: 171). For both Rorty and Davidson, the difference between metaphors and other expressions of language does not lie "deep within the noise itself" but it is precisely a function of how the expression operates in a community. When a specified meaning becomes more widely associated with a particular metaphorical expression - a development Rorty calls "a process of familiarization" - that expression can be used to express a specified belief and it can thus begin to serve as a reason for belief. In the course of this process, the metaphor gradually becomes "stale," in the sense that the similarities and ways of connecting associated with the metaphor become fixed. As a result, the metaphor loses its dynamicity and unpredictable character, that is, precisely those qualities that initially inspired Rorty to attach such a high value to metaphors in his postmetaphysical culture.

However, the process of familiarization is not completely a negative happening. Though becoming stale, the metaphor nevertheless enriches a community with a particular and novel way of making sense of the surrounding world or, as Rorty himself puts it, the familiarization of a metaphor enlarges "logical space" (ibid.: 124). Rorty maintains that we may find the insights some metaphors afford "so compelling that we try to make them candidates for belief, for literal truth" (ibid.). In other words, we try to make more and more people familiar with the interpretation of the metaphor we have found significant and to make them assign to it the same expressive content as we do. Now the value of the process of familiarization for the capacities required in the enhancement of solidarity lies in the fact that the metaphor's becoming familiar to a larger group of people requires, within a community, a more wide-ranging utilization of imaginative mental capacities. Without this sort of more extended use of imagination from the members of a community the particular outlook associated with the metaphor could not become fixed as widely as is required in the process of the metaphor's crossing the line from an unfamiliar noise to becoming a part of our patterns of justification. The metaphor must first become common currency for the community, so to speak, before it can enlarge logical space. A communal use of imagination is precisely what is required in incorporating a metaphor into a community. Thus, metaphors are not only significant as unfamiliar noises that cause surprising cognitions and that as a result make us reweave our web of beliefs and desires but the way in which metaphors become more widely used and familiar to a community has its own valuable outcomes as well. 


\section{Rorty and the Prospects of Pragmatist Aesthetics}

Explicating the cultural significance Rorty attaches to metaphors through the naturalistic understanding of their functioning he draws from Davidson's view provides new insights into the value metaphors may have for the liberalist goals characterizing Rorty's social philosophy. It also reveals some new aspects in Rorty's work related to aesthetics, for example that it includes emphases and ideas similar to those found in some other pragmatist-inspired aesthetic theories. This conclusion, I believe, has some wider implications for the place of pragmatism within contemporary aesthetics. Below, I shall sketch some of those implications.

One might think that pragmatist aesthetics would be one of the most flourishing traditions of contemporary aesthetics. Consider, for example, that one of the major figures of pragmatist philosophy, John Dewey, wrote a treatise on aesthetics, Art as Experience, which is marked by a richness and breadth of concern with very few equals in other philosophical traditions. Pragmatism's prospects for providing an interesting outlook on aesthetics is also shown by a claim Dewey presented in 1930, which proclaimed that the next great era of philosophy "will emerge when the significance of the social sciences and arts has become the object of reflective attention in the same way that mathematical and physical sciences have been made the objects of thought in the past, and when their full import is grasped" (Dewey 1980/30: 18). Yet, pragmatism's position within contemporary aesthetics does not correspond to the expectations these factors create. The tradition of Anglo-American aesthetics is still dominated by analytic aesthetics which has sometimes understood itself as a direct reaction against the murkiness and conceptual inaccuracies that Dewey's aesthetics has been considered to be characterized by. ${ }^{3}$

Pragmatism's significance for aesthetics, however, has not yet been examined in full. If Rorty's views are not after all plagued by the kinds of problems Shusterman insists they are, it might be the case that precisely the Rortian themes raised in this paper are able to open up previously unexamined pathways for pragmatist aesthetics. One important reason why I believe these themes are worth a more detailed examination is that the aspects of Rorty's philosophy of literature relating to the social and cultural function of art and the aesthetic the above reading reveals, overlap in some significant ways with the central tenets of John Dewey's aesthetic theory. Rorty and Dewey just use a partly different terminology in connection with them, Rorty addressing them in terms of metaphor, while Dewey talks about imagination.

Imagination has an important part in Dewey's aesthetics. For Dewey, "aesthetic experience is imaginative" (ibid.: 272). What I take Dewey to mean by this is that in aesthetic experience different individual elements form a complex unity and imagination is precisely the capacity that makes this tying possible. "When old and familiar things are made new in experience, there is imagination [...]," writes Dewey (ibid.: 267). Dewey emphasizes the communal and cultural importance of imagination, and some moral philosophers and philosophers of education have developed the Deweyan conception of imagination further in their own fields. Dewey's aesthetics has also been considered in these contexts, ${ }^{4}$ though not that thoroughly. Given the important position of imagination in Dewey's aesthetic theory, these fields are arguably important for pragmatist aesthetics 
as well, and the ideas introduced in them can bring new viewpoints and issues to pragmatist aesthetics.

It is however important to note with regard to an examination of the relevance of Rorty's work for aesthetics that Dewey's and Rorty's difference is only terminological. Rorty uses the concept of metaphor to tap into problems similar to those Dewey addresses. This is not a surprise, given that metaphor and imagination have a similar structure, namely to show something in a new light. In fact, in some of his later works, Rorty explicitly addresses the theme of cultural development through the notion of imagination, and he ascribes to that faculty the same kind of cultural role that he in his earlier works assigned to metaphors. ${ }^{5}$ In this respect, it is highly likely that Rorty's neopragmatism is able to make an important contribution to a pragmatist view of aesthetics emphasizing the social and cultural significance of imagination and aesthetic experience.

Developments also in philosophy of literature open up new prospects for pragmatism. In his recent work Fiction and the Weave of Life, John Gibson presents a multifarious critique of analytic philosophy of literature, which in many respects relies on ideas similar to those central to forms of pragmatism. The critical edge of Gibson's work is directed to a tradition in analytic aesthetics in which the issue regarding the cognitive value of literature is framed as the problem of the referents of fictive names and how fictional sentences can possess truth-content. The major shortcoming Gibson sees in this tradition is that it approaches the problem of fiction too narrowly as a purely semantic question (Gibson 2007: 6-7). Gibson's goal is not to provide a more successful analysis of the semantics of fictive uses of language but to undermine the position of this set of questions in attempts to shed light on the cognitive value of literature. He tries to open up a wider outlook on the relationship of fictional works to reality than semantic approaches provide. A central feature of Gibson's critique is to show that the conception of language underlying the received understanding of the problem of fiction is too heavily bound to the idea that language's capacity to represent the world serves as its source of meaningfulness. In this conception, language is in other words understood as a picture of reality. Fictional language appears problematic from this perspective precisely because it does not represent any worldly affairs (ibid.: 50-5).

As a basis for his criticism, Gibson offers an alternative picture of how language is connected with reality. He draws heavily on the philosophy of language of the later Wittgenstein in which the meaningfulness of language is explained in terms of the various roles pieces of language have in the rule-guided language games making up our linguistic community. Where Gibson sees the value of Wittgenstein's ideas to lie is precisely in their presentation of "a thoroughly social, cultural conception of language," which makes it possible to abandon the metaphysical commitments regarding the relationship between language and world involved in the language as a picture of reality conception (ibid.: 60).

Especially the reflections Wittgenstein puts forth on the standard metre stored in the Paris Archive are important for Gibson's aims. In his view, Wittgenstein's example is a particularly illuminating case of how there are other ways of being in connection with reality than through representation. According to Wittgenstein, the standard metre is a peculiar object in the respect that "one can say neither that it is one metre long, nor that it is not one metre long [...]" (Wittgenstein 2001/1953: $\$ 122$ ). This is to say that the standard metre is not an instance of a metaphysical entity "being one metre long," but it itself explains what it means to be one metre long. With his peculiar description of the 
standard metre, Wittgenstein's aim in Gibson's view is not to ascribe some property to the object. Rather, it is intended to draw attention to "the role the standard metre has in the practice of measurement" (Gibson 2007: 64). The standard metre is not a representation of a metre; it provides the standards for representing something as being one metre long and in this respect it is a means of giving structure to the world and one's experience of it.

Gibson's explanation of how fictional works of literature connect with reality builds upon the Wittgensteinian analysis of the standard metre. The events fictional works portray should not be understood as representations of real world events but, like the standard metre, they are to be understood as providing standards for a group of concepts by which we represent the world. A decisive difference between the standard metre and works of literary fiction, however, is that the cultural concepts, that is, such concepts as "love," "suffering," "exploitation," and "devotion," the contents of which literary works illuminate, are more complex than the practice of measuring and the concepts it includes. The standards for the concepts which Gibson sees as the focus points of literary fiction are not grounded on an unequivocal object "but upon very elaborate visions of human life" (ibid.: 71). Despite their complexity, it is, nevertheless, possible to formulate some standards for the application of these concepts and for Gibson, the narrative traditions of different cultures, by presenting us "refined, varied, and complex possibilities of perception and description," serve as the archives for constructing standards for their application (ibid.). For example, Gibson argues that in Notes from Underground, Feodor Dostoevsky brings to our attention a suffering that "arises from a condition of mind in which one's self and one's world come to appear at once alien and revolting." Gibson continues by noting that Dostoevsky's work does not present a "mimetic duplication" of a case of suffering but in reading it we are engaged with "an object that is constitutive of a way in which we can see our world [...]." In this respect, literary works have a kind of primacy to representation. They do not themselves represent cultural practices but rather they form a ground for making sense of them (ibid.: 129).

Within the confines of this article, it is impossible to give a more detailed examination of Gibson's view of fiction. What is more interesting in this context is to observe the overlaps between Gibson's philosophy of literature and pragmatist philosophy and aesthetics. It is for example noteworthy that the critical attitude towards the problem of fiction Gibson takes is in many respects similar to Rorty's. Like Gibson, Rorty criticizes approaches to fiction which treat it primarily as a question about the semantics of fictive sentences. Rorty focuses on the tradition stemming from Bertrand Russell's analysis of fictive sentences. For Rorty, too, it is central to reveal that this approach to fiction is tied to an understanding of language in which linguistic items are seen to derive their meaning from a relationship of representation to worldly objects and state of affairs, in other words precisely the same picture view of language that according to Gibson has dominated the issue regarding the cognitive significance of fiction (Rorty 1982/81: 110-4). Moreover, the cure Rorty offers for overcoming this framework is precisely the same as Gibson's, namely the late Wittgensteinian view of language as a cluster of language games (ibid.: 129). For Rorty, its significance is precisely in that it involves a wholly different view of how language is connected with reality than the picture theory of language presents. Once the late Wittgensteinian view is embraced, the very meaningfulness of the questions found central to a successful analysis of the cognitive value of literature in the contemporary discussion on fiction in Rorty's opinion evaporates. That is, "philosophical 
problems about fiction simply do not arise once the picture picture is dropped," argues Rorty (ibid.: 130). This, again, is very much in line with Gibson's position.

There are also other points of contact between Gibson's philosophy of literature and pragmatist philosophy and aesthetics. First, Gibson opposes dualisms and separations similar to those different forms of pragmatism have tried to overcome, and second, besides the later Wittgenstein, Gibson cites other figures who have been associated with the pragmatist tradition, such as Wilfrid Sellars, whose critique of empiricism and the distinction between the space of causes and the space of reasons it includes forms an important part of Gibson's critical examination of contemporary analytic philosophy of literature (Gibson 2007: 54-5, 61). Finally, Gibson's attempt to see fiction in a wider perspective than as a purely semantic question can be seen to be at least partly similar in spirit to Davidson's attempt to move the problem of metaphor outside the pale of semantics.

What, however, is noteworthy is that despite these overlaps in his book Gibson nowhere discusses pragmatist accounts of art and the aesthetic at length. Rorty and Shusterman are mentioned only in passing and Dewey's views are not discussed at all. This oversight is a shame, for by providing a multifarious picture of the ways in which works of art are connected with aspects of human life different forms of pragmatism give a possibility for a highly systematic account of literature's relationship to reality, and hence they can supplement Gibson's account. A more detailed development of this pragmatist view of literature needs to be left for another occasion. However, it is my belief that the naturalistic conception of metaphor Rorty draws from Davidson's work and the view of literature's social role he develops on the basis of it will form a significant part of this more fully-fledged pragmatist account. In this respect, my view of the relevance of Rorty's work for aesthetics and philosophy of art is quite different from Shusterman's.

\section{BIBLIOGRAPHY}

BRANDOM R., (2000), "Vocabularies and Pragmatism: Synthesizing Naturalism and Historicism," in Brandom R. (ed.), Rorty and His Critics, Oxford, Basil Blackwell.

DAVIDSON D., (1984/1978), “What Metaphors Mean," in Davidson D., Inquiries into Truth and Interpretation, Oxford, Clarendon Press.

DAVIDSON D., (2001), Subjective, Objective, Intersubjective, Oxford, Clarendon Press.

DEWEY J., (1980/34), Art as Experience, New York, Perigee Books.

DEWEY J., (1960/30), “From Absolutism to Experientialism," in Bernstein R. (ed.), On Experience, Nature, and Freedom: Representative Selections, New York, Library of Liberal Arts.

FESMIRE S., (2003), John Dewey and Moral Imagination. Pragmatism in Ethics, Bloomington, Indiana, Indiana University Press.

ISENBERg A., (1987), “Analytical Philosophy and the Study of Art," Journal of Aesthetics and Art Criticism 46, 125-36. 
GIBSON J., (2007), Fiction and the Weave of Life, Cambridge, Cambridge University Press.

LEDDY T., (2005), “Dewey’s Aesthetics," Stanford Encyclopedia of Philosophy.

MALECKI W., (2010), Embodying Pragmatism. Richard Shusterman's Philosophy and Literary Theory, New York et. al., Peter Lang.

RORTY R., (1979), Philosophy and the Mirror of Nature, Princeton, New Jersey, Princeton University Press.

RORTY R., (1982/81), “Is there a Problem about Fictional Discourse?,” in Rorty R., Consequences of Pragmatism, Minneapolis, Minnesota University Press.

RORTY R., (1989), Contingency, Irony, and Solidarity, Cambridge, Cambridge University Press.

RORTY R., (1991), Objectivity, Relativism, and Truth, Cambridge, Cambridge University Press.

RORTY R., (2007), Philosophy as Cultural Politics, Cambridge, Cambridge University Press.

SHUSTERMAN R., (1997), Practicing Philosophy, New York, Routledge.

Shusterman R., (2000), Pragmatist Aesthetics. Living Beauy, Rethinking Art. Second Edition, New York, Rowman and Littlefield.

SHUSTERMAN R., (2002), Surface and Depth. Dialectics of Criticism and Culture, Ithaca \& London, Cornell University Press.

SHUSTERmAn R., (2006), “Aesthetic Experience: From Analysis to Eros," The Journal of Aesthetics and Art Criticism, 64 (2), 217-29.

TARTAGLIA J., (2007), Rorty and the Mirror of Nature, New York, Routledge.

WILliams M., (2009), "Introduction to the Thirtieth-Anniversary Edition," in Rorty R., Philosophy and the Mirror of Nature. Thirtieth-Anniversary Edition, Princeton and London, Princeton University Press.

WitTGENSTEIN L., (2001/1953), Philosophical Investigations, 2nd edition, trans. G. E. M. Anscombe, Oxford, Basil Blackwell.

\section{NOTES}

1. See, for example, Brandom (2000: 160-1), Tartaglia (2007: 126), Williams (2009: xxvii-xxix).

2. For example, in his recent monograph (Malecki 2010) on Shusterman's aesthetic theory, Wojcieh Malecki discusses neither Rorty's naturalism nor the effect Davidson's conception of metaphor had on Rorty's philosophy of literature.

3. For example, Arnold Isenberg called Dewey's Art as Experience "a hodgepodge of conflicting methods and undisciplined speculations" (Isenberg 1987: 128). For more on the reception of Dewey's work within analytic aesthetics see Leddy 2005.

4. See especially Fesmire 2003.

5. See Rorty 2007. 


\section{ABSTRACTS}

This paper outlines a pragmatist aesthetic theory on the basis of themes relating to naturalism, metaphor, and solidarity found in Richard Rorty's neopragmatism. A central part of this attempt is to show that some previous readings of Rorty's work in aesthetics are misguided. I begin by raising aspects of Rorty's work that have been previously largely overlooked in aesthetics and philosophy of art, and which I believe undermine particularly Richard Shusterman's critical reading of Rorty. I shall then move on to discuss the social role Rorty assigns to metaphors in his postmetaphysical liberalist culture and argue that the social and cultural view of art and the aesthetic Rorty's philosophy of literature contains overlaps in some significant respects with some central points of John Dewey's pragmatist aesthetics. I close by outlining some new set of issues for pragmatist aesthetics that emerge from the discussion of Rorty's work presented in the paper.

\section{AUTHOR}

\section{KALLE PUOLAKKA}

University of Helsinki

kalle.puolakka[at]helsinki.fi 